\title{
Investigation into potential impacts of implementation of water sensitive urban design components
}

\author{
S. Shrestha, A. Samuel, P. Ronaldson \& S. J. Riley \\ Sustainable Engineering and Technology Research Group, \\ School of Engineering, University of Western Sydney, Australia
}

\begin{abstract}
Water Sensitive Urban Design (WSUD) involves integration of water cycle management into urban planning and design. Stormwater runoff management has been identified as one important aspect of water cycle management - both in terms of infrastructure cost and sustainable environmental management. The claim that WSUD addresses undesirable impacts of traditional stormwater management plus anticipated future severe drought forecasts have resulted in increased use of WSUD components by planners and developers as well as regulators and policy and decision makers. However, the potential adverse impacts of WSUD have yet to be fully explored. One result of WSUD implementation is the reduction in volume of water reaching receiving waters. This has the potential to adversely impact the eco-system. This paper models the potential reduction in storm water reaching receiving waters from a rainfall event when WSUD is applied to a catchment and lists potential adverse ecological impact.
\end{abstract}

Keywords: Water Sensitive Urban Design (WSUD), hydrological modelling, Run-Off Routing Burroughs (RORB).

\section{Introduction}

Stormwater runoff management has been identified as one important aspect of water cycle management. In urban planning, it plays a significant role both in terms of infrastructure cost and sustainability of the environment. Undesirable impacts of traditional stormwater management plus anticipated future severe 
drought forecasts have resulted in increased use of WSUD components by planners and developers as well as regulators, policy and decision makers.

Water Sensitive Urban Design (WSUD) is aimed at minimising the hydrological impact of urban development to the surrounding environment. It involves reducing water demands and finding alternative water sources, minimising waste water generation and treating it to a suitable standard for reuse and/or release into receiving waters. The process includes treating urban stormwater to a water quality enabling reuse and/or discharge to surface waters, and using stormwater to maximise visual and recreational amenity in the urban landscape.

The main objectives of WSUD include protection of natural systems, integration of stormwater treatment into the landscape, protection of water quality, reduction of run-off and peak flows, and addition of value while minimising development costs. Barton and Argue [1] divide WSUD into two broad categories, namely stormwater management and wastewater management.

One result of WSUD implementation is the reduction in the quantity of water reaching receiving waters. This has the potential to adversely impact the ecosystem. Undesirable ecological and environmental impacts of reductions in water flow have already been established [2,3]. However, the potential adverse impacts of WSUD implementations have yet to be fully explored. This paper aims to bridge this gap by investigating potential impacts of WSUD application. This is achieved through simulation of changes in flow volumes (resulting from a pre-defined storm event) reaching receiving waters when WSUD elements are implemented. The change in flow volume resulting from implementation of WSUD elements in a Western Sydney catchment is analysed.

\section{Model selection}

A hydrological model simulates catchment response under various conditions. The overall purpose of a hydrological model is to provide a representation of a drainage system (catchment) and its response to different input conditions [4]. While several models are available to simulate precipitation-runoff processes, some of the commonly used models (in Australia) include Model for Urban Stormwater Improvement Conceptualisation (MUSIC), E2, Hydrological Engineering Centre - Hydrological Modeling System (HEC-HMS), Storm Water Management Model (SWMM), and Run-Off Routing Burroughs (RORB). The following sections briefly present requirements and capabilities of these models.

MUSIC was developed in Australia in 1999 as a part of an urban stormwater quality program of the Cooperative Research Centre for Catchment Hydrology $(\mathrm{CRCCH})$. It can simulate both quantity and quality of runoff from urban catchments, is applicable to catchments ranging in areas from $0.01 \mathrm{~km}^{2}$ to $100 \mathrm{~km}^{2}$ and uses time intervals between six minutes and 24 hours [5]. Its ease of use has encouraged wide application of the model around Australia [6]. It is noted that MUSIC does not incorporate all aspects of stormwater management.

The E2 model is one of the latest hydrological models developed by $\mathrm{CRCCH}$, as part of an Australia-wide modelling framework. The model assesses the 
hydrologic impact of various land-uses and water management practices in a catchment. Results include runoff and pollutant loads. Effectiveness of implementation of actions to improve water quality can also be simulated [7]. The model has a flexible structure that allows the user to select the level of complexity desired. The simulation can cover between 10 and 100 subcatchments. Alternate processes occurring in the system can be simulated for each component. The overall results include flow and pollutant load of constituents at any point in a channel network at a desired time [8]. The model cannot be used in situations involving complex water management or regulated systems. In addition, robustness of the model has yet to be established.

HEC-HMS, developed by the United States Army Corps of Engineers (USACE) under the Civil Works Development program, simulates precipitationrunoff processes of a dendritic watershed system. It is capable of modelling areas ranging from small urban or natural watershed to large river basins. The hydrographs produced can be directly used in conjunction with other software for studies on water availability, urban drainage, flow forecasting, future urbanisation impacts, reservoir spillway design, flood damage reduction, floodplain regulation, and systems operation [9]. The model is capable of simulating watersheds under various environmental and land development conditions. The model's robustness has been proven through its world-wide application; e.g. Australia, India, Middle Eastern nations, Spain, Tanzania and the USA.

SWMM was originally developed by the United States Environmental Protection Agency (USEPA). It is a dynamic rainfall-runoff simulation model and can be used for both the single event as well as continuous simulation. The model output include flow rate, flow depth and temporal distribution of water quality parameters [10]. The simulation incorporates various aspects of the urban hydrologic and quality cycles including rainfall, snowmelt, surface and subsurface runoff, flow routing through drainage networks, storage and treatment. This model is commonly used in planning and design of urban drainage networks, especially for large areas with numerous sub-catchments [11]. SWMM has been used extensively in various countries around the globe including Australia, Canada, European nations and the USA. This model is known for its ability to handle complex hydraulic conditions including combined sewer overflow. However, excessive input data requirements have limited the use of this model.

The RORB model is designed to simulate general runoff and routing to be used in the calculation of flood hydrographs from rainfall and other channel inputs [12]. The model can be applied in both the rural and the urban catchments and is suited for evaluation of the effect of changing land-uses [13]. A Graphical User Interface (GUI) makes the model user-friendly. In addition, input data requirement is minimal. A schematic representation of the model is provided in Figure 1. In Australia, the runoff routing model (RORB) has been widely used to simulate extreme flood events and to evaluate the effects of changing landuses. Owing to its ease of use and minimal input data requirement, RORB was selected for this study. 


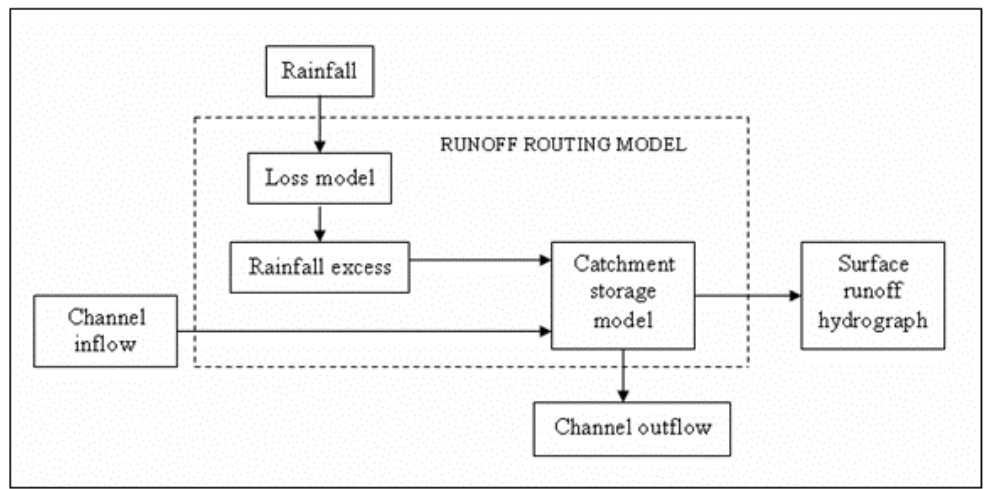

Figure 1: $\quad$ Schematic-RORB [11].

\section{Study area}

South Creek Catchment, with an area of $620 \mathrm{~km}^{2}$, is located approximately 40 $\mathrm{km}$ west of the Sydney Central Business District (CBD) (Fig. 2). It is one of the major tributaries of the Hawkesbury-Nepean River system. The study covers an approximate area of $94 \mathrm{~km}^{2}$ of the South Creek catchment. Termed as the Upper South Creek Catchment, the area extends from Narellan in the South to Badgerys Creek in the North (approx. $17 \mathrm{~km}$ ) and from Bringelly in the West to Rossmore in the East (approx. $4 \mathrm{~km}$ ) (Fig. 2). It is drained by South Creek and its tributaries (Rileys Creek, Lowes Creek, and Thompsons Creek).

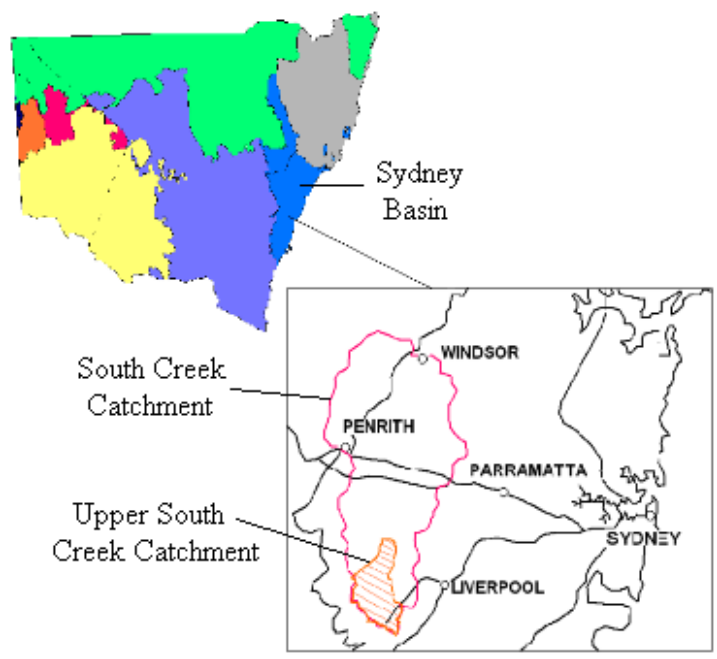

Figure 2: $\quad$ Location map - South Creek and Upper South Creek catchments. 


\section{Model calibration and verification}

MapInfo Professional was used to extract the physical data of the catchment. The rain gauge station at Whitlam Centre (station no. 067035) near Liverpool was used to analyse and extract the pluviograph data [14] (Fig. 3).

For this study, the storm events during July and August were selected, to capture the effect of a drier period. During this period, cooler temperatures are experienced. The model was calibrated using the storm event of 5-10 August 1998 (Figure 4). Time 0-hr on Fig. 4 refers to 12am, 5 August.

Monthly Rainfall Pattern ( $\mathrm{mm}$ )

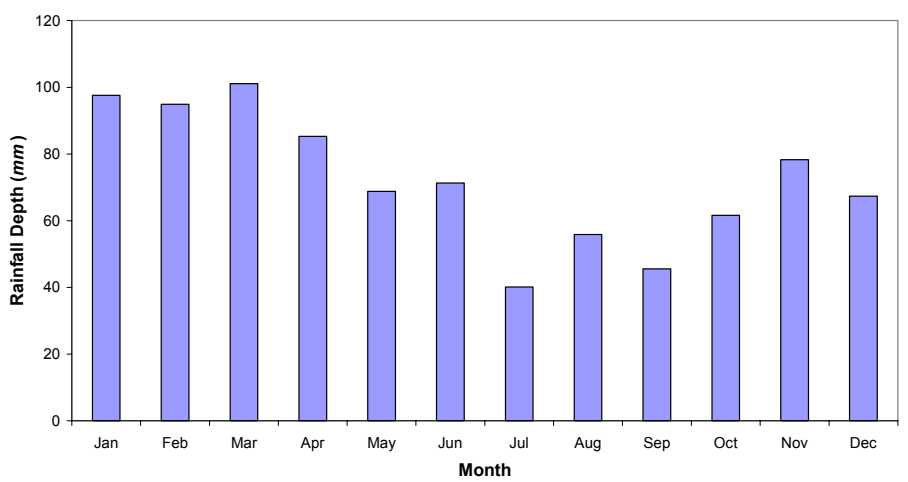

Figure 3: Rainfall pattern [13].

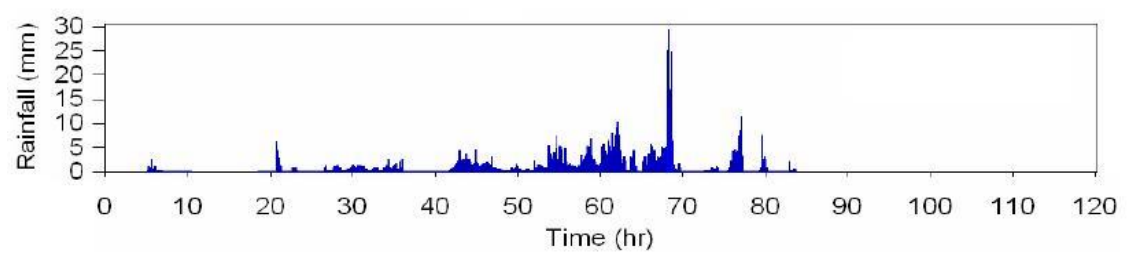

Figure 4: Rainfall depth (calibration run).

The $\mathrm{k}_{\mathrm{c}}, \mathrm{m}$, and initial loss parameters were estimated to match simulated and observed peak discharges as well as the time to peak. This resulted in the values of $119.5,0.8$ and $20 \mathrm{~mm}$ as $\mathrm{k}_{\mathrm{c}}$, $\mathrm{m}$, and initial loss, respectively.

The model was verified using observed rainfall and flow data for the 23-31 July 2001 storm event (Fig. 5) - time 0 -hr on Fig. 5 represents 12 am on $23^{\text {rd }}$ July 2001. Output from the calibration and the verification runs are shown in Figures 6 and 7, respectively. Model parameters were tuned to match the peak discharge and the time to peak between simulated and observed values. As can be seen from Figures 6 and 7, there is a good match between observed and simulated peak discharge values. It is also noted that the time to peak between observed and simulated values match. 


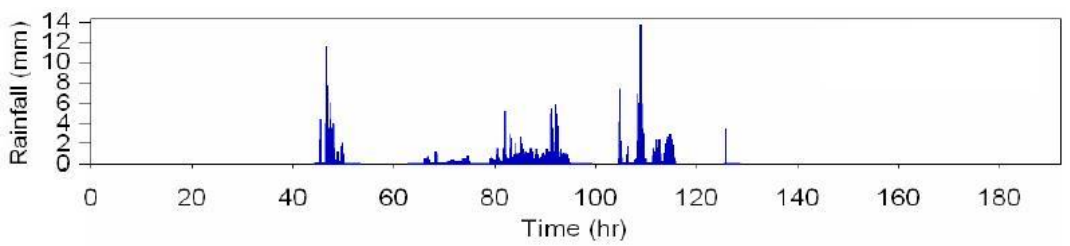

Figure 5: $\quad$ Rainfall depth (verification run).

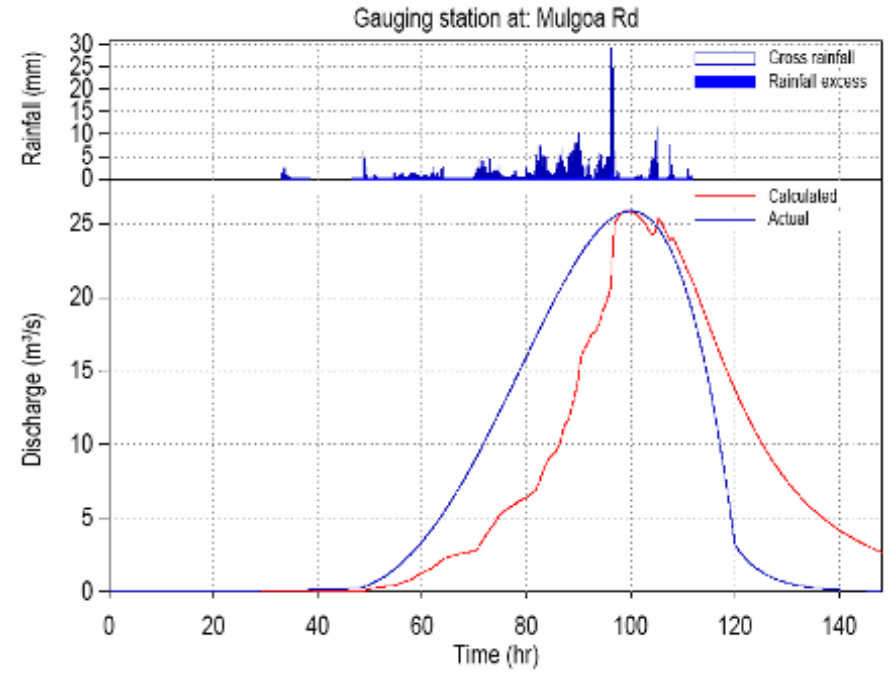

Figure 6: Calibration run.

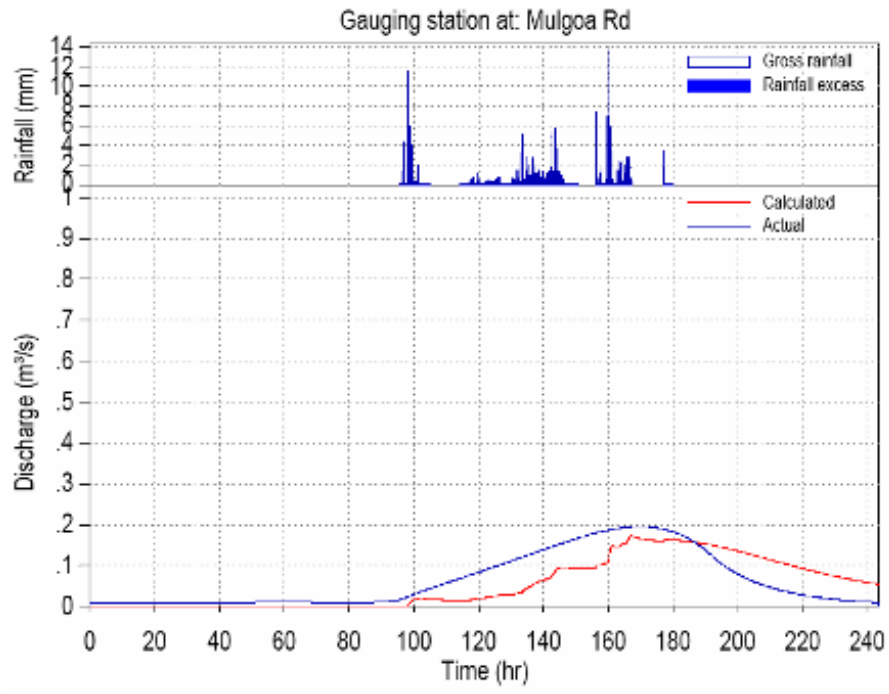

Figure 7: Verification run. 


\section{Sensitivity analysis}

The calibrated RORB model was used to simulate different land-use changes caused by the implementation of WSUD elements. Runoffs resulting from the catchment before and after WSUD element implementations were simulated. The different catchment conditions modelled included the catchment in natural state and that with varying degrees of developments - represented via changes in runoff coefficient. Runoff coefficients were changed between natural state and as high as five times that of natural state. Simulation of catchment conditions after the WSUD element implementation included the catchment with a decreased initial loss with varying runoff coefficients, an increased initial loss with varying runoff coefficients (represents WSUD implemented to a lesser extent), maximum initial loss with varying runoff coefficients (represents the maximum amount possible to be retained by WSUD components), and no loss (fully retained). Results of the various scenarios are presented in Table 1.

\section{Discussion and conclusion}

Table 1 indicates that an increase in runoff coefficient linearly increases the discharge volume. The runoff volume versus the runoff coefficient multiplier presented above for the scenarios simulated show that the values are about the same. It can therefore be deduced that, overall, there is not much of a difference in the amount of water reaching the receiving waters.

Based on the results of the simulation, it can be concluded that it is unlikely for the volume of water reaching the receiving waters to be greatly affected by WSUD implementation. The percentage changes in runoff volume in both preand post- implementation of WSUD are about the same. Simulation results for differing implementation of WSUD elements suggest that there will be a slight difference which could be deemed negligible.

It is important to note that the present study has a number of limitations resulting from the following assumptions:

- Storage effects in channels are neglected and the overland flow components are lumped in with the storage effects of the more significant channels.

- The catchment is assumed to be non-linear with the value of $\mathrm{m}$ taken as 0.8 .

- The calibrated value of $\mathrm{k}_{\mathrm{c}}$ is assumed as 119.5 and was applied to all scenarios.

- Changes in runoff coefficient represent changes in WSUD elements.

These limitations mean the need to extend this study by accounting for changes in all input parameters. It is, therefore, recommended that further study be conducted to see whether this change in water volume reaching receiving waters over time will impact on the ecological environment as the studies 


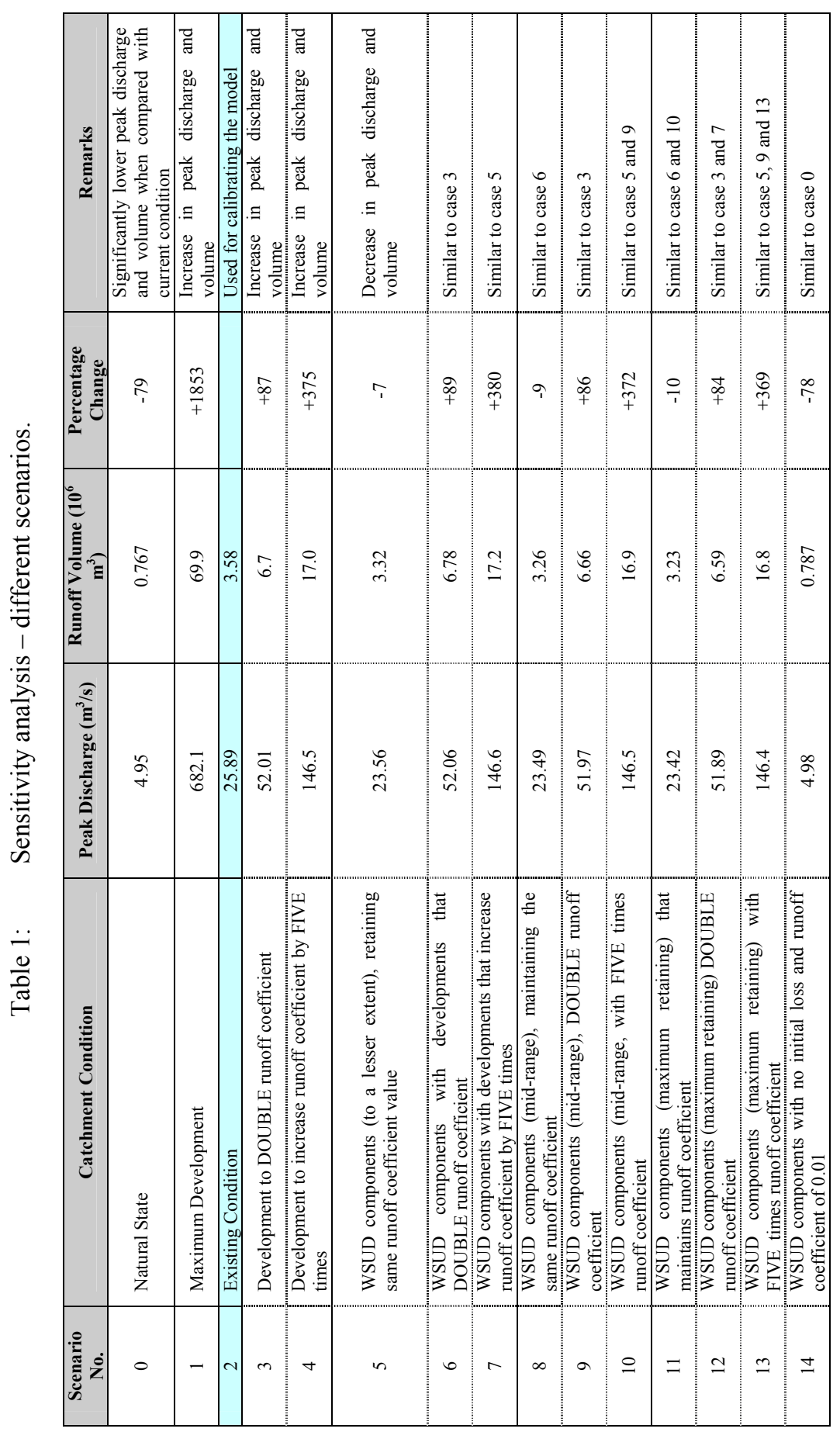


presented by Chow-Fraser [2] and Papastergiadou et al. [3] have shown that even slight changes over time can make an impact on the ecological environment. As this study only presents hypothetical scenarios of the application of WSUD to a catchment, further validation of the study in functional catchments with varying ranges of WSUD implemented should be considered.

\section{References}

[1] Barton, A. B., and Argue, J. R. A Review of the Application of Water Sensitive Urban Design (WSUD) to Residential Development in Australia, Australian Journal of Water Resources, 11(1), pp. 31-40. 2007

[2] Chow-Fraser, P. 'Ecosystem response to changes in water level of Lake Ontario marshes: Lessons from the restoration of Cootes Paradise Marsh', Hydrobiologia, 539(1), pp. 189-204. 2005

[3] Papastergiadou, E. S., Retalis, A., Kalliris, P. \& Georgiadis, T. Land use changes and associated environmental impacts on the Mediterranean shallow Lake Stymfalia, Greece, Hydrobiologia, 584(1), pp. 361-372, 2007

[4] Butler, D. \& Davies, J. W. Urban drainage, 2nd ed, Spon Press, New York, 2004

[5] Wong, T. H. F., Fletcher, T. D., Duncan, H. P., Coleman, J. R. \& Jenkins, G. A. A Model For Urban Stormwater Improvement Conceptualization, in The Biennial Meeting of the International Environmental Modelling and Software Society, Lugano, Switzerland.2002

[6] Wong, T. Urban Stormwater Quality, Monash University, Victoria, Australia. Retrieved 1 May 2007, <http://www.catchment.crc.org.au /projects/projects9902/outcomes/4.1.pdf>. 2004

[7] Argent, R. M., Grayson, R. B., Podger, G. M., Rahman, J. M., Seaton, S. \& Perraud, J. M. E2 - A Flexible Framework For Catchment Modelling, in MODSIM 2005 International Congress on Modelling and Simulation. Modelling and Simulation Society of Australia and New Zealand (MSSANZ), Melbourne, Australia, December, 2005.

[8] Argent, R. M., Podger, G. M., Grayson, R. B., Fowler, K. \& Murray, N. E2 Catchment Modelling Software: User Guide, CRC, Australia. 2004

[9] USACE. Hydrologic Modeling System HEC-HMS Quick Start Guide Version 3.0.0 December 2005, Hydrologic Engineering Centre, Davis, California. 2005

[10] Mays, L. W. Stormwater collection systems design handbook, McGrawHill, New York. 2001

[11] Rossman, L. A. Storm Water Management Model User's Manual Version 5.0, USEPA, Cincinnati, Ohio, 2005

[12] Laurenson, E. M., Mein, R. G. \& Nathan, R. J. RORB Version 5 Runoff Routing Program User Manual, Monash University and Sinclair Knight Merz, Australia. 2006 
[13] Singh, V. P. \& Woolhiser, D. A. 'Mathematical model of watershed hydrology', Journal of Hydrology Engineering, vol. July/August 2002, pp. 270-292. 2002

[14] Bureau of Meteorology. Average Monthly Temperature and Rainfall, Retrieved 20 October 2007, <http://www.bom.gov.au/climate/averages /tables/cw_067035.shtml>. 2007 